\title{
Opportunities and challenges of e-portfolios in teacher education. Lessons learnt
}

\author{
Alexandra Totter ${ }^{\mathrm{a}}$, Corinne Wyss ${ }^{\mathrm{b}}$ \\ ${ }^{a}$ Zurich University of Teacher Education (PH Zürich), Switzerland, alexandra.totter@phzh.ch, \\ https://orcid.org/0000-0001-7231-9596 \\ ${ }^{b}$ Zurich University of Teacher Education (PH Zürich), Switzerland, corinne.wyss@phzh.ch
}

\begin{abstract}
Portfolios are often used in higher education for learning, promotion, assessment and appraisal. Thanks to technical developments in recent years, portfolios are increasingly digital rather than physical. E-portfolios provide a comprehensive way to document personal progress, to reflect on work activities, to support learning and to serve as a tool for feedback and evaluation. However, there has been very little research conducted on the use of e-portfolios for learning purposes in higher education. This paper focuses on the use of e-portfolios in teacher education. Six students in a master programme work with e-portfolios in the course of their practical vocational training. In a mixed-methods design, the students were interviewed about their experiences and the process of writing e-portfolios. In addition, a document analysis of the e-portfolio entries has been conducted in terms of content and structure. The findings of this study provide indications on how e-portfolios can be used effectively in teacher training and which promoting and inhibiting conditions students encounter.
\end{abstract}

Keywords: E-portfolio, teacher education, mixed-methods design

\section{Introduction}

The work of teachers is characterized by a broad spectrum of tasks and activities - from teaching, educating, assessing and advising to personal and professional development (Rothland \& Terhart, 2007). Reaching a professionalization to deal with all the tasks demands a work-related development in which the necessary knowledge, skills and attitudes are acquired. Practical vocational training within the framework of teacher training is a central element in supporting students in the development of their work-related professionalization. Thus, students get to know possibilities and methods for planning, analyzing and reflecting on their own lessons in a structured way and develop them further. The assignments of practical vocational training are closely linked to the professional mandate of teachers (Heitzmann \& Messner, 2001) and address, among other things, questions on lesson planning and implementation, various teaching and learning arrangements, basic diagnostic and didactic techniques, class leadership and learning process support as well as current questions on the occupational field of education and the institution of "school".

The use of digital media and tools in teacher education not only offers new opportunities for supporting teaching and learning processes but also poses new challenges to the professional development of teachers. Therefore, their use must be part of the overall didactical concept of a curriculum and need to be carefully integrated into teaching. Wherever digital media and tools are merely added to existing curriculum concepts, students perceive this as additional effort without recognizing the benefits (Trager, 2012).

This paper explores the use of e-portfolios in teacher education and more specifically addresses the questions of how e-portfolios can be used effectively in practical vocational training and which promoting and inhibiting conditions students encounter.

\section{Working with e-portfolios in teacher education}

The use of portfolios in teacher education is not a new phenomenon. Since the beginning of 2000, their use in German-speaking countries has been a topic in relation to school teaching. In the following years, its use was also implemented in teacher training (Koch-Priewe, 2013). In this section, the possibilities and goals of utilizing portfolios 
in teacher education are illustrated and an approach developed for a consecutive master programme for primary school teachers is presented.

\subsection{Different kinds of e-portfolios in teacher education}

"Portfolio" is a heterogeneous concept, and there is a multitude of types and variations, such as working portfolio, process portfolio, showcase portfolio or application portfolio. Despite this diversity, it can be noted that a distinction is generally made between learning portfolios, assessment portfolios and presentation portfolios (Koch-Priewe, 2013). The presentation portfolio typically serves as a demonstration of completed work, the assessment portfolio is usually predefined by lecturer as it is to be reviewed and graded, and the learning portfolio evolves usually based on learner needs (Evans \& Powell, 2007).

Portfolios can be created by individual learners or by groups of learners; they can be composed of paper or digitally. E-portfolios have advantages over printed portfolios, as they are easily accessible, time and place independent, can integrate multiple media, are easy to update and can more readily reference the work of learners. In addition, eportfolios can be private or public, with the owner deciding who gets access to which levels of content (Amaya, Agudo, Sánchez, Rico, \& Hernández-Linares, 2013; Mohammed, Mohssine, M’hammed, Mohammed, \& Abdelouahed, 2015).

In e-portfolios, learners can trace the development of their thinking and learning over time and show those competencies to their lecturer. Moreover, e-portfolios provide digital resources relevant to learners' own activities, as well as for collaboration and feedback (Malita, 2009). In teacher education, the e-portfolio can thus document the student's journey in becoming a teacher: "Preservice students select, share, and reflect on artifacts such as educational philosophies, classroom management plans, unit and lesson plans, plans to meet the needs of diverse and special needs pupils, and video clips of practice teaching" (Strudler \& Wetzel, 2005, p. 412). This type of portfolio is referred to as learning portfolio. Based on constructivist theories of learning and development, an intensive examination of learning contents and experiences is encouraged, which should support the development of metacognitions. By providing learners with a high degree of autonomy and self-regulation, the learning process becomes an individual process of knowledge acquisition (Hascher \& Sonntagbauer, 2013). Students are expected to take responsibility for selecting artefacts, describing, analyzing and evaluating evidence, making connections to standards and interpreting their own learning (Strudler \& Wetzel, 2005).

Empirical studies on traditional portfolios and particularly on e-portfolios show that portfolio work can support this integration and promote professional "teacher reflection" (Schön, 1983). The basic assumption here is that professional development is particularly supported by critical examination of personal experiences. Through reflection, it is possible to take a conscious look at one's own activities, which makes visible strengths and weaknesses and leads to learning and development. A primary goal of working with e-portfolios in teacher education is the integration of biographical, subject-specific and didactical knowledge. However, this only succeeds if the e-portfolios are linked to suitable learning tasks and are embedded in an institutionally meaningful way (Keller, 2014).

Despite the above-mentioned advantages, students often criticize the high investment in time required for composing portfolio entries, and previous studies also indicate that mentorship, guidance and support mechanisms are often insufficient with the quality of portfolios suffering as a result (Evans \& Powell, 2007). Overall, it must be stated that there is still little research on the use of portfolios for formative and learning purposes in higher education over a longer period of time (Klenowski, Askew, \& Carnell, 2006; Pecheone, Pigg, Chung, \& Souviney, 2005; Evans \& Powell, 2007; Bryant \& Chittum, 2013).

\subsection{Theoretical educational framework of practical teacher training and e-portfolio use}

The practical vocational training in the consecutive master for primary school teachers at Zurich University of Teacher Education comprises a total of 12 ECTS. The part-time study usually takes six semesters, and students work alongside as secondary school teachers. Therefore, the master programme bears in mind that the students already have teaching experiences at the beginning of their studies, as they have already a bachelor's degree in primary education. With deliberately controlled cycles of personal position determination, feedback and evaluation and personal development goal setting, the programme strives to support students in reaching a level of professional development as high as possible by the end of their training and also to equip students to successfully seek out further development by themselves beyond the end of their studies. In this context, the practical training focuses, on the one hand, on expanding competence through class observation, feedback and reflection and, on the other hand, on specific themes and areas of secondary school-level knowledge. The concept of vocational training is therefore based on a constructivist learning theory and the assumptions of reflective learning (Brooks \& Grennon Brooks, 1999; Schön, 1983). Students are thus seen as active participants in their learning and meaning making (Lewis, 2017). They should, supported by appropriate inputs from the lecturers and building on their already existing competencies and experiences, be able to expand their own professional knowledge.

In learning groups, the students work with different tasks, such as writing blog entries, discussing video clips of own teaching sessions, getting pupil feedback or doing work shadowing. At the end of every semester, students are encouraged to compose an e-portfolio entry using the software Mahara. A learning e-portfolio has been designed 
following a co-constructive approach, specifically considering that professionalization processes have a high degree of diversity due to the different competence requirements and learning strategies. Another assumption is that "students construct knowledge that has meaning in their real worlds so that their study is intrinsically significant and does not just consist of evidence that they can do well in university examinations" (Klenowski et al., 2006, p. 278).

\section{Research questions}

It is our concern to monitor and evaluate the e-portfolio work of the students in the consecutive master for primary teachers. The findings are expected to provide insight into the opportunities and challenges of using learning eportfolios in teacher education. Based on the considerations outlined earlier, the following research questions are investigated:

- How do students experience e-portfolios and describe the process of creating e-portfolios?

- Which promoting and inhibiting conditions are mentioned by the students?

\section{Research design}

\subsection{Participants}

At the beginning of autumn 2017, two men and four women, aged 20, 27, 28, 30 and 54.5 years, started the consecutive master. ${ }^{1}$ The students have already been working as teachers between 3 and 25 years. Five students indicated that they have been teaching between 1 and 5 years at secondary level. One student has teaching experience at the lower level, three students at the intermediate level and one student has experience in the field of German as a foreign and contemporary language. A survey was conducted in the first semester, collecting data on media competence and previous portfolio experience. Students reported advanced media competence in word processing and presentation creation, basic to advanced competence for areas such as image processing, handling learning platforms and social media, and little media competence in creating teaching materials and websites and in the use of blogging as well as professional social networks. Two students indicated that they have no previous experience in using portfolios. Both completed their primary teacher education before 2011. Three students created paper portfolios (presentation portfolios) at the end of their teacher education. One person had worked with e-portfolios before using the software Mahara during his/her primary teacher training.

\subsection{Method}

This study pursues an explorative approach, using a mixed-methods approach (Creswell \& Plano Clark, 2018) with the intent of a convergent design to obtain different but complementary data (ibid. p. 68) to answer the research questions. Right from the beginning of the consecutive master, students were informed about the accompanying study. They agreed to participate and gave their consent for the researchers to get access to their data on Mahara. At the end of the second semester, after the second e-portfolio entry was composed, guided one-on-one interviews with the students took place. Before the interviews were conducted, the student activities on Mahara were examined. In particular, a document analysis of all e-portfolio entries was performed. The results of this analysis were also used for individualized questions during the interviews. All interviews were undertaken by the two authors and transcribed afterwards. After an opening question, students were asked to discuss the following topics:

- Goal of working with portfolio in teacher education in general and specifically working with e-portfolios;

- Approach of composing the first and the second e-portfolio entry (these questions were individualized based on the analysis of the actual e-portfolio entries of each student);

- Personal challenges and benefits of creating e-portfolio entries;

- Usability of the software Mahara, perceived advantages and disadvantages.

The qualitative analysis of the interviews was based on the structured content analysis according to Kuckartz (2018). The category system was developed using a deductive-inductive approach. In a two-step procedure of category formation and coding, the material was deductively coded along the following three main categories based on the literature (e.g. Bryant \& Chittum, 2013):

- Students' experience with feelings and opinions about e-portfolios;

- $\quad$ Process of writing e-portfolio entries;

- Usability of technology.

In the second step, the subcategories were inductively developed and differentiated to describe the main categories in detail and cross-checked with the results of the analysis of the e-portfolio entries. The two authors carried out the content analysis following a consensus procedure. The interviews will continue to take place in the fourth and sixth

\footnotetext{
${ }^{1}$ One student has been granted leave in the meantime.
} 
semester and the small number of students allows the document analysis of all e-portfolio entries over the entire course of studies.

\section{Results}

The results of the document analysis of the students' portfolio entries (Section 4.1) reveal structural elements in terms of content and length. In Section 4.2, the main findings from the oral interviews with the students are presented.

\subsection{Document analysis of e-portfolio entries}

The structural characteristics of the first and the second e-portfolio entry of each student were analyzed to get an insight into the constructive as well as co-constructive activities of the students (Klenowski et al., 2006; Lewis, 2017). An overview of the topics and the length of the e-portfolio entries are presented in Table 1. The length of the entries varies between 827 and 2441 words. The analysis also reveals that there is an increase in the length between the first and the second e-portfolio entry. The entries address different topics; communication issues, lesson planning and implementation. However, these topics were not mentioned by the students during the interview as having a strong personal relevance to their everyday (work) life. All entries are accessible for all students, and the commenting function is available. Nevertheless, not a single comment from students on entries from peers has been found. During the interviews, the students confirmed that no comments were made, stating that they had at least read some of the peers' entries.

Table 1. Topics and lengths of e-portfolio entries.

\begin{tabular}{llll}
\hline & Entry & Topic & \# words \\
\hline Student 1 & 1 & Ability to distance oneself - Distinction & 827 \\
\hline & 2 & Communication & 1506 \\
\hline Student 2 & 1 & Planning and implementation of lessons & 1988 \\
\hline Student 3 & 1 & Romansh versus English lessons & 2166 \\
\hline & 2 & Dyspraxia* & 2441 \\
\hline Student 4 & 1 & Quizlet/Kahoot - Planning and implementation of lessons & 2389 \\
\hline & 2 & Ability to take criticism \& anger management* & 1860 \\
\hline Student 5 & 1 & Communication & 2839 \\
\hline & 2 & Heterogeneity & 1196 \\
\hline
\end{tabular}

*Subjective importance and strong relevance to students' everyday (work)life in the interviews.

\subsection{Interviews with the students}

The results of the analysis of the interviews are presented along the three main categories outlined in Section 3.2: the students' experience as well as the process of writing e-portfolios and the usability of technology.

In general, students find the portfolio work useful and valuable, nevertheless they experience e-portfolios in different ways. Although some students see privileges in working with an e-portfolio, other students prefer to work offline.

"Yeah, I am, I'm just used to do it differently. (.) I take my notes, I have a journal,... in school, and... I, well, I don't begin to make now everything online. Well, maybe, I'm a little different type." (translated by the authors, student 1 , 39:39)

"I think it's great, I only work with electronic devices during my studies. From this perspective, uh, I think it's definitely the future." (translated by the authors, student 5, 95:95)

The students consider the advantage of e-portfolios in the fact that contents can be seen and edited from any location, that different persons can gain insight and that contents can be retrieved more easily.

Overall, the process of composing an e-portfolio entry is not a simple task. Students find it difficult to come up with a suitable topic. They stress that "writing about something" must be of subjective importance and need to have strong relevance to everyday life. If this is not the case and a given or an invented topic has to be addressed, the portfolio work makes little sense for the students. 
"And, I think, the problem is that sometimes you don't have something where you say: boah, that's what I want to do! And then, you just have to look for something artificial and then it's much harder than if you have a topic, that you really want." (translated by the authors, student 3, 109:109)

"Yes, that's the first difficulty: What do I choose from all these things that bother me? And, uh, a colleague was then able to give me a few tips." (translated by the authors, student 5, 69:69)

E-portfolio entries are perceived as a particular type of text, which challenge the students, since scientific writing is very unfamiliar to them.

"What's incredibly difficult for me is the scientific way of working with quoting and stuff. I don't know that, I don't need that, that's for me... Of course, I'm doing a university degree and and and... but I'll never have anything to do with it again. In the teaching profession, right?!" (translated by the authors, student 4, 99:99)

The multiple burden of studying and working is rather stressful for some students. This also has an impact on their portfolio work. They admit that the e-portfolio entries need to be composed as time-effectively as possible and that they do this work just before the deadline. However, students recognize this as less beneficial for their own learning process.

"Uh, no, there's no time to think about it at the moment. I think I'll write something about evaluation. Or something that I already do in class anyway and... a subject which I can quickly write about, where I can give a practical example. [] But I'm just thinking,... for time reasons I will take something which I already... know well and... yeah. That I can accomplish this work really fast." (translated by the authors, student 2, 71:71)

"But it's just, as I said,... that's just a bit because of me; in the end it's the end of the semester, I mean... there is a lot to do at the university. In addition, then you can... frankly, I then do it, rather over a... shorter period of time and then it's, I think, not so effective.... So yeah, you don't go into details like that." (translated by the authors, student 1 , 57:57)

The usability of technology was assessed rather critically. All students perceived the software Mahara as too complex. The number of features and settings is confusing, especially if one works with it only occasionally.

"It's complicated to work with. It takes a lot of time to get everything out, and you could use that time in a better way. Um,... maybe if you use it more often.... So, maybe if you study full time and need it all the time, it might be a good thing. But if you need it two or three times a year... then I think there are better possibilities." (translated by the authors, student 3, 127:127)

\section{Conclusions and Discussion}

Despite the fact that there is a large amount of research on e-portfolio in higher education, up to date little research focuses on the use of e-portfolio for formative and learning purposes in teacher education over a longer period of time (Hascher \& Sonntagbauer, 2013). As outlined earlier, this study follows an exploratory approach, gaining a deeper insight into students' experience with and the process of composing e-portfolios as part of their practical vocational training. In addition, the study investigates which promoting and inhibiting conditions students encounter.

The findings show that students are basically positive about the e-portfolio work. They mention, while composing the e-portfolio entries, that one consciously thinks about oneself and takes time to reflexively engage with one's own activities. However, students discuss various aspects that are challenging for them, such as finding a meaningful topic and the preparation of the portfolio entries.

As the results of the document analysis and the interviews reveal, writing e-portfolio entries "is not something that happens magically" (Ray \& Coulter, 2008). In line with the results of blog research (e.g. Nackerud \& Scaletta, 2008; Totter, 2018), it takes time, training as well as experience to get used to working with e-portfolios. Another difficulty lies in the fact that within the framework of practical vocational training there is little time dealing in depth with this digital form of professional "teacher reflection", since student teachers are generally very busy with their teaching activities. For this reason, it seems particularly important to implement the use of e-portfolios over a longer period of time and in different subject areas. Within that, it is also crucial to coordinate deadlines of entries in relation to the student's other workload.

A further aspect that becomes clear from the analysis is that the text form "e-portfolio entry" challenges the students. Students struggle with the selection of a topic and the search for and integration of scientific literature. Furthermore, they are requested "to put their journey in becoming a teacher" into a "scientific text". As Lester \& Paulus (2011) describe, this could be perceived by students as a contradictory demand to compose.

Finally, it needs to be stressed that the benefit and return for students only coincide if it is possible to establish a link to the subjective importance and relevance to everyday (work)life. When implementing e-portfolios in teacher education, students might need support at the beginning in establishing this link, and as Malita (2009) states "[] it is important to not only introduce the method, but to also implement e-portfolios as an overall concept".

The technical handling of the e-portfolio and the Mahara software was also perceived as challenging. Although the students received an introduction to the different elements of the software and technical support, most students expressed problems regarding the usability of the software. When using e-portfolios in an educational context, one must consider that students might have good media competences in terms of word processing and presentation creation, but rather little previous experience with e-portfolio software. It is therefore important to carefully choose the software and to select it according to the planned activities. 
The results of this study confirm findings from the literature and previous studies (Klenowski et al., 2006; Pecheone et al., 2005; Evans \& Powell, 2007; Bryant \& Chittum, 2013), although the students of this study already completed their education as primary school teachers and already have teaching experience. This makes it clear once again that composing e-portfolio entries and working co-constructive is not a trivial task even for advanced learners. It must therefore be emphasized once again that the initiation and guidance of such activities must be well thought out and implemented. Otherwise, working with (e-)portfolios becomes more of a burden for students than a meaningful, valuable activity.

The project will continue for 2 more years, and it will therefore be possible to further investigate the progress of students in using e-portfolios as a means to integrate biographical, subject-specific and didactic knowledge for their professional development.

\section{Acknowledgements}

The authors would like to thank the students at Zurich University of Teacher Education who participated and the staff who facilitated the study for their generous support.

\section{References}

Amaya, P., Agudo, J. E., Sánchez, H., Rico, M., \& Hernández-Linares, R. (2013). Educational e-portfolios: Uses and Tools. Procedia - Social and Behavioral Sciences, 93, 1169-1173. https://doi.org/10.1016/j.sbspro.2013.10.009

Brooks, M. G., \& Grennon Brooks, J. (1999). The Courage to Be Constructivist. Educational Leadership, 57(3), 18-24.

Bryant, L. H., \& Chittum, J. R. (2013). ePortfolio Effectiveness: A(n Ill-Fated) Search for Empirical Support. International Journal of EPortfolio, 3(2), 189-198.

Creswell, J. W., \& Plano Clark, V. L. (2018). Designing and conducting mixed methods research (Third Edition). Los Angeles: SAGE.

Evans, M. A., \& Powell, A. (2007). Conceptual and practical issues related to the design for and sustainability of communities of practice: the case of e-portfolio use in preservice teacher training. Technology, Pedagogy and Education, 16(2), 199-214. https://doi.org/10.1080/14759390701406810

Hascher, T., \& Sonntagbauer, C. (2013). Portfolios in der Lehrer/innenbildung - Bilanz, Rahmung und Ausblick. In B. Koch-Priewe, T. Leonhard, A. Pineker, \& J. C. Störtländer (Eds.), Portfolio in der LehrerInnenbildung. Konzepte und empirische Befunde. (pp. 287-298). Bad Heilbrunn: Klinkhardt.

Heitzmann, A., \& Messner, H. (2001). Die berufspraktische Ausbildung von Lehrpersonen. Eine Einführung in die Diskussion. Beiträge zur Lehrerinnen- und Lehrerbildung, 19(1), 5-16.

Keller, S. D. (2014). E-Portfolios als Lern- und Prüfungsinstrumente in der Lehrerinnen- und Lehrerbildung. Beiträge Zur Lehrerinnen- Und Lehrerbildung, 32(1), 120-134.

Klenowski, V., Askew, S., \& Carnell, E. (2006). Portfolios for learning, assessment and professional development in higher education. Assessment \& Evaluation in Higher Education, 31(3), 267-286. https://doi.org/10.1080/02602930500352816

Koch-Priewe, B. (2013). Das Portfolio in der LehrerInnenbildung - Verbreitung, Zielsetzungen, Empirie, theoretische Fundierungen. In B. Koch-Priewe, T. Leonhard, A. Pineker, \& J. C. Störtländer (Eds.), Portfolio in der LehrerInnenbildung. Konzepte und empirische Befunde. (pp. 41-73). Bad Heilbrunn: Klinkhardt.

Kuckartz, U. (2018). Qualitative Inhaltsanalyse: Methoden, Praxis, Computerunterstützung (4. Auflage). Weinheim Basel: Beltz Juventa.

Lester, J. N., \& Paulus, T. M. (2011). Accountability and public displays of knowing in an undergraduate computermediated communication context. Discourse Studies, 13(6), 671-686. https://doi.org/10.1177/1461445611421361

Lewis, L. (2017). ePortfolio as pedagogy: Threshold concepts for curriculum design. E-Learning and Digital Media, 14(1-2), 72-85. https://doi.org/10.1177/2042753017694497

Malita, L. (2009). E-portfolios in an educational and occupational context. Procedia - Social and Behavioral Sciences, l(1), 2312-2316. https://doi.org/10.1016/j.sbspro.2009.01.406

Mohammed, A., Mohssine, B., M'hammed, E. K., Mohammed, T., \& Abdelouahed, N. (2015). Eportfolio as a Tool of Learning, Presentation, Orientation and Evaluation Skills. Procedia - Social and Behavioral Sciences, 197, 328333. https://doi.org/10.1016/j.sbspro.2015.07.145

Nackerud, S., \& Scaletta, K. (2008). Blogging in the academy. New Directions for Student Services, 2008(124), 71-87. https://doi.org/10.1002/ss.296

Pecheone, R. L., Pigg, M. J., Chung, R. R., \& Souviney, R. J. (2005). Performance Assessment and Electronic Portfolios: Their Effect on Teacher Learning and Education. The Clearing House: A Journal of Educational Strategies, Issues and Ideas, 78(4), 164-176. https://doi.org/10.3200/TCHS.78.4.164-176

Ray, B. B., \& Coulter, G. A. (2008). Reflective Practices Among Language Arts Teachers: The Use of Weblogs. Contemporary Issues in Technology and Teacher Education, 8(1), 6-26. 
Rothland, M., \& Terhart, E. (2007). Beruf: Lehrer - Arbeitsplatz: Schule. In M. Rothland (Ed.), Belastung und Beanspruchung im Lehrerberuf (pp. 11-31). https://doi.org/10.1007/978-3-531-90500-6_2

Schön, D. (1983). The reflective practitioner. How professionals think in action. New York: Basic Books.

Strudler, N., \& Wetzel, K. (2005). The Diffusion of Electronic Portfolios in Teacher Education: Issues Of Initiation and Implementation. Journal of Research on Technology in Education, 37(4), 411-433. https://doi.org/10.1080/15391523.2005.10782446

Totter, A. (2018). Weblogs in der Hochschullehre. Chancen und Herausforderungen. MedienPädagogik: Zeitschrift für Theorie und Praxis der Medienbildung, 81-117. https://doi.org/10.21240/mpaed/00/2018.12.30.X

Trager, B. (2012). Förderung von Selbstreflexion bei pädagogischen Professionals mit Hilfe von E-Portfolios. Friedrich-Alexander-Universität Erlangen-Nürnberg, Erlangen-Nürnberg. 